\title{
Violencias en la educación y la urbanidad: el caso de Londrina, Brasil
}

\author{
Ana Claudia Duarte Pinheiro* \\ Edward Rodrigo Sánchez Malagón *** \\ Neiva Camargo Torrezani
}

La problemática de las violencias se dirige a la forma en que se desarrolló la historia de la ciudad de Londrina, Brasil, a partir de uno de los equipamientos públicos escogidos para el análisis, la Biblioteca Pública Municipal. La provisión de un servicio bibliotecario y mantenimiento de un espacio público aparentemente indican un eficiente servicio público, pero ocultan el deterioro y poca relevancia concedidos por las instituciones estatales encargadas de la educación pública y la historia de la ciudad. Esto da pie a las violencias estructurales y emergentes en el espacio público londrinense.

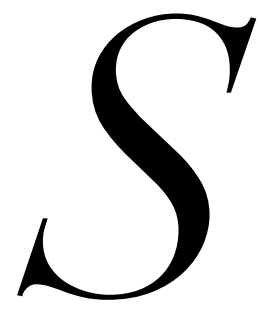

IGUIENDO LA METODOLOGÍA de revisión de literatura, búsqueda en internet y trabajo de campo en el centro de Londrina, situada en el norte de Paraná, sur de Brasil, se investigó el tema de la violencia estructural manifestada en la falta de inversión en edificios públicos vincu-

* Profesora del posgrado en Derecho de la Universidad Estadual de Londrina, Brasil.

** Estudiante de Maestría en Geografía de la Universidad Estadual de Londrina, Brasil.

*** Estudiante de maestría en Geografía de la Universidad Estadual de Londrina, Brasil.

Traducción del portugués de Guadalupe Margarita González Hernández. lados a la educación y la cultura, y, como consecuencia de esa conducta, la violencia emergente de un deficiente servicio público de acceso a la información.

Desde la memoria protegida en un panel existente frente a la Biblioteca Central del campus de la Universidad Estatal de Londrina (Universidad Estadual de Londrina), que ha sido restaurado por profesores y estudiantes de Arquitectura y Urbanismo de la misma Universidad, comienza la construcción de la discusión sobre la importancia de la educación para la preservación de la memoria cultural de la ciudad en su interfaz con la violencia estructural y emergente.

El relato histórico sobre la ciudad de Londrina alude desde sus características agrícolas tradicionales en la antigüedad, y más tarde, la incorporación de la 
agricultura mecanizada. La diversificación en el campo se reflejó en la ciudad, sometida a profundos cambios, lo que confirma la concentración de la población y la tendencia hacia la integración vertical que llegó desde la región central de la ciudad, así como la incorporación de la prestación de servicios como uno de sus talentos a expensas de la plena industrialización. Londrina es el municipio y localidad urbana más grande entre veintiséis municipios que conforman el área metropolitana, símbolo de la creación de una región que supera el millón de habitantes (véase figura i). derancia de la población urbana sobre la rural. Se estima que más de zo por ciento de la población mundial habita en los cascos urbanos de las ciudades. El proceso de asentamiento y habitación en espacios urbanos no ha sido ajeno a múltiples tensiones que giran alrededor de condiciones de vida en grandes núcleos urbanos, a la organización y uso del espacio, el territorio, entre muchos otros. En algunos de estos conflictos, la violencia ha irrumpido y permanecido como un elemento central y característico de gran impacto en el

FiguRA

Mapa de localización del municipio de Londrina, estado de Paraná, Brasil

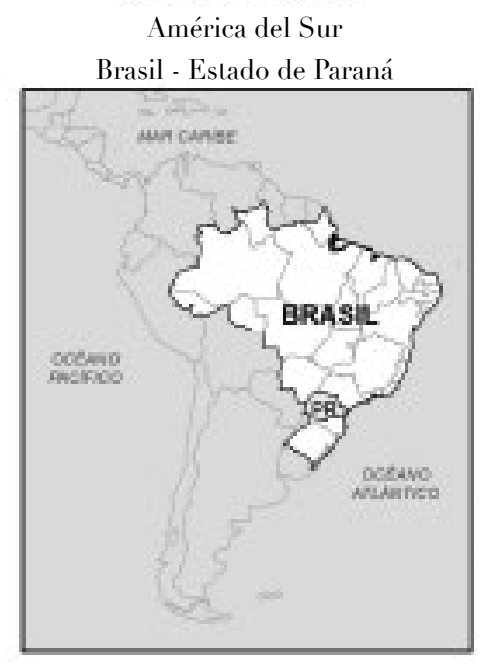

El posicionamiento geográfico, comercial y cultural de Londrina ayuda a atraer flujos relevantes de personas que buscan mejorar su calidad de vida, pero no siempre es posible identificar las condiciones de sostenibilidad que trascienden las condiciones individuales y llegan a la comunidad.

\section{URBANIZACIÓN DE LA VIOLENCIA}

La discusión sobre el modelo de desarrollo económico aplicado en los países latinoamericanos y sus implicaciones en la seguridad humana ha demostrado que las ciudades manifiestan y generan violencias. Un ejemplo son los tipos de violencia urbana exhibidos en la mayoría de estos espacios urbanos producto de la expansión urbana desordenada. Este fenómeno da lugar a la urbanización de la violencia.

Una de las características más relevantes de la dinámica poblacional hoy a nivel mundial es la prepon- devenir de la vida de sus pobladores, afectando la realización y ejercicio de los Derechos Humanos.'

No obstante la discusión de la violencia urbana, generalmente no lleva a distinguir sus manifestaciones: "El problema de la delincuencia es un fenómeno complejo que debe ser abordado tomando en cuenta su naturaleza multicausal. De esta manera, dentro de los factores que se han relacionado con el aumento de la criminalidad, se encuentran los socioeconómicos, demográficos, geográficos, políticos y culturales". ${ }^{2}$

Se traducen en amenazas a la seguridad humana, en la medida en que no nutren el pleno desarrollo de las actividades físicas, materiales y espirituales que contribuyen al crecimiento personal del individuo ni permiten acciones para la transformación social. La falta de seguridad económica representa una persistente amenaza de la pobreza; la inseguridad alimentaria da pauta al hambre crónica; la inexistencia o precarie- 
dad de la salud propician enfermedades mortales; la falta de cuidado del medio ambiente genera su degradación; la inseguridad comunitaria induce tensiones sociales, étnicas y religiosas, e incluso el terrorismo e inseguridad política conducen a la represión política. ${ }^{3}$

Las violencias emergentes casi siempre se manifiestan en forma física, fácilmente identificables y percibidas en la vida cotidiana de las personas en las ciudades. Por el contrario, las violencias estructurales asociadas al modelo de desarrollo aplicado en estos países y manifestado en la estructura física y organizativa de sus espacios urbanos son consideradas como estigmas de su desarrollo humano, ya que este tipo de violencia es alimentada en gran parte por la desigualdad socioeconómica que priva en la región latinoamericana.

Las violencias emergentes se manifiestan a través de la cuantificación y evidencia en asaltos, asesinatos, disputas por narcotráfico, etcétera, y por lo tanto generan gran inseguridad, miedo y opresión al residente urbano. En tanto, la violencia estructural urbana se genera a partir de los problemas de acceso, distribución y disputa de infraestructura, transporte, servicios de educación, salud y otros ocasionados por la forma organizativa de la ciudad misma.

John Gledhill, al tratar el tema de seguridad humana menciona variadas relaciones de poder que traducen la reproducción de las desigualdades sociales:

Como resalta Graça Druck (20II), a pesar de los cambios positivos de los últimos años, continúa siendo grande el desafío para mejorar una situación en que, en 2009, la mitad de los trabajadores brasileiros no disfrutaba de los derechos garantizados por la firma de la cartera de trabajo y casi sesenta por ciento de la población económicamente activa aún se encontraba en una situación precaria.Para reflexionar sobre estas cuestiones, necesitamos analizar cualitativamente los procesos de cambio en la sociedad, en las relaciones sociales y en los imaginarios sociales en esta fase del desarrollo del capitalismo. Desde mi punto de vista, esa perspectiva hace de la desigualdad (no de la pobreza) un asunto clave. Aunque las personas experimenten la pobreza como una carencia material, ella resulta de arreglos sociales que afectan la distribución de la renta de bienes, es decir, que se refiere a una estructura de las relaciones de poder. ${ }^{4}$

Esta discusión sacó a la luz una serie de problemas urbanos existentes en la ciudad de Londrina, Brasil, que a menudo pasan inadvertidos. Con el apoyo de estos conceptos, se fue capaz de identificar estos tipos de violencias existentes dentro de la estructura de relaciones de poder que evidencian desigualdades sociales en el espacio urbano.

En la actualidad, con una población de alrededor de 5433 mil habitantes, Londrina, localizada en el estado de Paraná, presenta varios casos de violencia, tanto emergentes como estructurales. Un ejemplo es el comercio de los vendedores ambulantes, que aunque considerados ilegales judicialmente, son importantes para el desarrollo económico de la ciudad.

En Londrina, como en la mayoría de las ciudades brasileñas, dicho comercio se concentra en espacios privados (rentan un local), a menudo sin ninguna formalidad legal, pero con el apoyo del gobierno y sus reglas de espacios públicos regulados se les genera una licencia de negocio y su autorización oficial para instalarse temporalmente sin conceder derechos al emprendedor informal; sin embargo, sus condiciones son precarias (espacios pequeños e insalubres, sin posibilidades de expansión, control de horarios) y sufren de estigma social (véase figura 2).

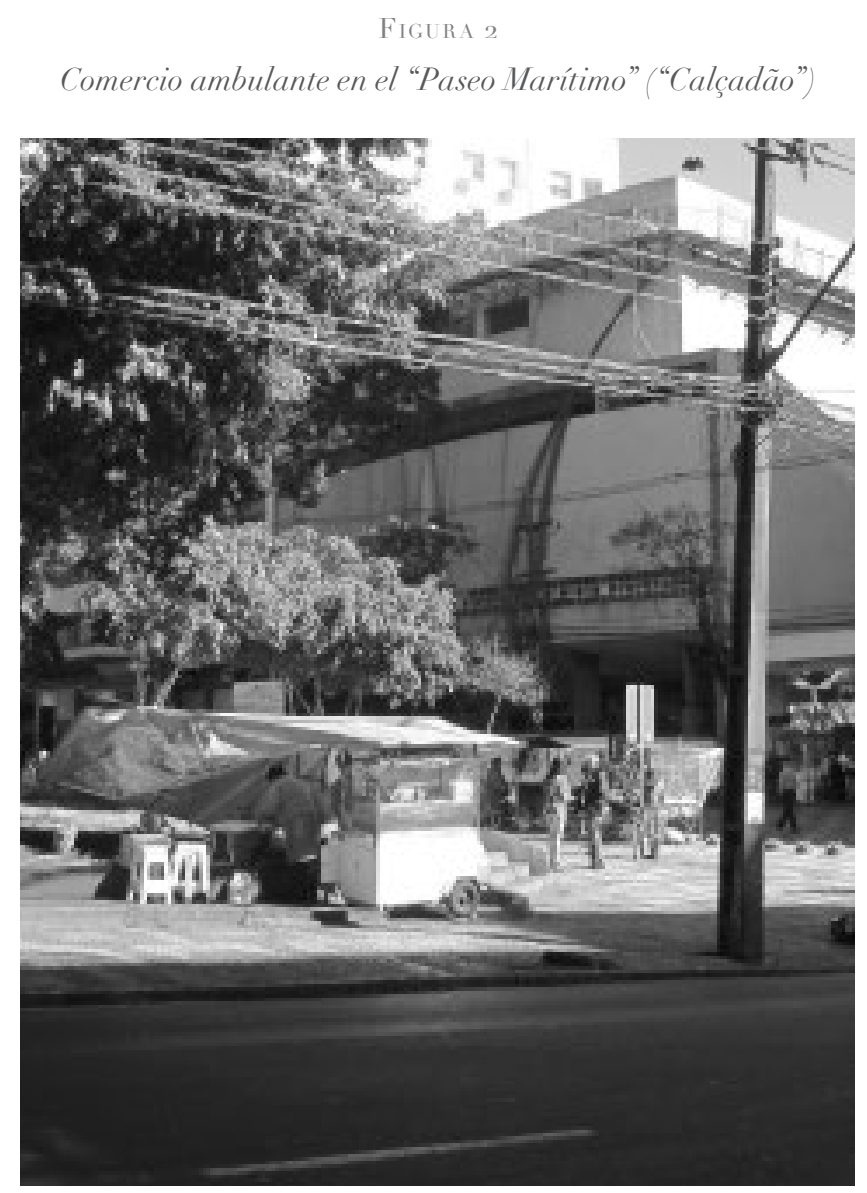

Principal avenida central de Londrina próxima al Teatro Universitario Oro Verde (Ouro Verde). Fotografía: Edward Rodrigo Sánchez Malagón. 
Otro ejemplo es el edificio público que incluye una de las actividades más importantes para la educación y la cultura de los ciudadanos, así como sus condiciones improvisadas, que sin duda influye en la formación y desarrollo de la ciudadanía: la biblioteca pública. Por lo tanto, el modelo de desarrollo llevado actualmente está desalentando las actividades culturales y educativas a través de la calidad del acceso a la Biblioteca Pública Municipal, situación que se reflejará en la vida de la ciudad en su conjunto y de sus residentes.

\section{SOBRE LA HISTORIA DE LA CIUDAD:}

EL MURAL RECUPERADO

El panel situado justo enfrente de la Biblioteca Central en el campus de la Universidad Estatal de Londrina (véase figura 3) es uno de los iconos más importantes de la historia municipal. Se trata de un mural construido con azulejos pintados a mano que retratan la evolución de la ciudad. Inicia, en una primera fase, justo antes de la década de los años treinta hasta la década de los cincuenta, cuando la ciudad estaba en pleno apogeo, con una población superior a límites proyectados previamente. Dicho panel, además de su importancia artística, describe en sus dibujos la trayectoria a través de la cual fue reconocida como el desarrollo urbano en la región.
Londrina es expresión de la aventura en el proceso de ocupación del norte del estado de Paraná. Fueron los ingleses quienes en la década de los veinte abrieron la puerta para que otros pioneros y exploradores que cruzaban el río Tibagi llegaran a este lugar para construir la "Little London" [...] Londrina, la capital del café $[. .$.$] fue planeada en Londres e implementada por$ la Compañía de Tierras del Norte de Paraná (Companhia de Terras Norte do Paraná, CTNP) para que fuera la capital del área de colonización y la sede de la gestión de esa compañía en el norte de Paraná.

La tala de bosques para el nacimiento de una nueva ciudad se torna imprescindible en la primera parte del diseño y la construcción de casas y edificios en calles demarcadas en forma organizada y planificada es su característica esencial. Ante el auge del café dicha planeación fue insuficiente porque "la ciudad de Londrina, inicialmente diseñada para contener 20 mil habitantes", pronto superó las previsiones iniciales "en sus primeros veinte años de existencia" ${ }^{6}$ y, hoy en día, con un poco más de ochenta años de vida, todavía joven, cuenta con una población estimada de aproximadamente 537 mil personas, según datos publicados por el Instituto Brasileño de Geografía y Estadística (Instituto Brasileiro de Geografia e Estatística, IBGE) para el año 2013.7 "El rápido crecimiento de Londrina se de-

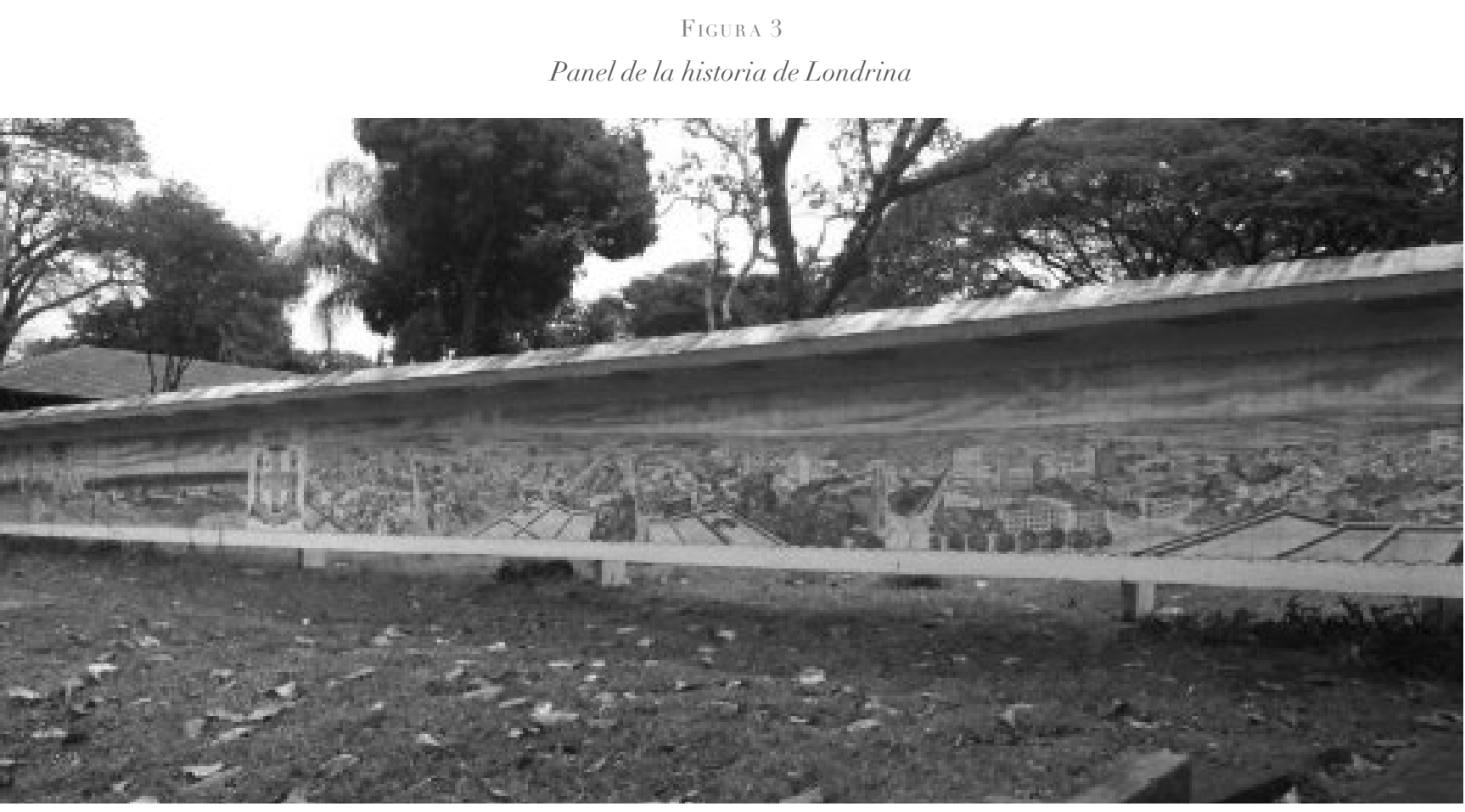

El panel se localiza en uno de los jardines de la Universidad Estatal de Londrina, Londrina, Brasil. Fotografía: Ana Claudia Duarte Pinheiro. 
bió principalmente a la fuerte producción agrícola referente a la cafetalera que generó una atracción de capitales hacia la región y sirvió como su base económica hasta la década de los años setenta". 8

Conocida como la capital mundial del café a finales de la década de los años setenta, Londrina sufrió el fin de una era de progreso económico sin precedentes, producto de la afectación de la helada negra ocurrida en 1975 y terminó con las plantaciones de café.

La segunda fase del mural expresa los cambios físicos, económicos y sociales producidos en la ciudad desde el inicio de la producción de café hasta la prestación de servicios y, sobre todo, de actividades relacionadas al uso del suelo, en particular a la especulación. Lo que hoy sigue siendo una de sus características:

En la década de los años ochenta, hubo cambios importantes relacionados con el uso del suelo en la zona urbana de Londrina, en especial en la región central, a través de la revitalización del espacio anteriormente construido, lo que trajo nueva configuración a la ciudad. El proceso de integración vertical es una característica importante de esta década, se produjo principalmente con la construcción de edificios residenciales en el eje central de la ciudad y sus alrededores. 9

Hoy, Londrina es la ciudad que conserva sus características agrícolas de antaño, pero con la incorporación de cultivos mecanizados, como la soya y el maíz, que ya se proyectaban desde los años sesenta como relevantes y, más recientemente, el cerco construido a través de las plantaciones de caña de azúcar. La ciudad de Londrina ante este apogeo agrícola, se especializó en la provisión de servicios. La diversificación en el campo se reflejó en la ciudad y su estructura, que se sometió a profundos cambios, bajo la construcción vertical; fenómeno que, en la actualidad, se ha adaptado a las nuevas dinámicas del modelo de desarrollo implantado bajo la forma de nuevos espacios no sólo de tipo residencial, sino comercial y de provisión de servicios con un estímulo a las inversiones públicas y privadas necesarias. "Con la búsqueda del desarrollo de la región, miembros de la Asociación Comercial de Londrina (Associaçâo Comercial de Londrina, ACL), en la década de los años sesenta, comenzaron una campaña para la industrialización de Londrina, anticipando que después de la gran helada de 1975 no habría diversificación en el campo". ${ }^{\circ}$
El mural que protege una parte de la historia de la ciudad, casi convertido en chatarra en la década de los ochenta, después de que fue retirado de la sede del gobierno municipal (Prefeitura Municipal) por obras de remodelación, fue recuperado por un profesor y alumnos de la carrera de Diseño y Arquitectura, cuyo trabajo dedicado y meticuloso permitió rescatarlo casi al Ioo por ciento. Acción que fue ignorada por las autoridades municipales. Desde entonces, se encuentra en frente del edificio de la Biblioteca Central en el campus de la Universidad Estatal de Londrina.

$\mathrm{Al}$ poner de relieve este hecho se evidencia la violencia estructural intrínseca en la actuación estatal que se muestra insensible a la representación de la historia de Londrina e ignora los esfuerzos para preservar el arte y la memoria de la ciudad, se intentaba descartar un monumento como si no tuviera valor. A pesar de que este mural no refleja plenamente la realidad de la ciudad en los periodos involucrados como el fenómeno que se expresa en la siguiente cita, sí es considerado un hito de la historia de Londrina por sus residentes. "A partir de los años sesenta y setenta, con la sustitución del café, la mecanización de la agricultura y la concentración de la tierra, fue la liberación de una creciente población que vive en zonas rurales que se dirigió a la zona urbana y que fue incapaz de absorber toda la mano de obra, generando población desempleada cuya miseria fue creciendo"."

Si se observa este hecho desde la educación implica también violencia estructural al definir la institución estatal qué tipo de historia se quería implantar en Londrina. El papel de la institución de educación superior (Universidad Estatal de Londrina) fue darse cuenta del agravio y recuperar el panel como una oportunidad para mejorar conocimientos de rescate y aplicarlos en la práctica, lo que mantuvo viva la colección de arte e historia de Londrina.

\section{La Educación SEgún la Biblioteca Pública Municipal}

El edificio de la antigua Biblioteca Pública Municipal, después de las exitosas remodelaciones hechas en la década de los ochenta en todo el centro de Londrina, pasó al mandato del Departamento de Cultura del municipio de Londrina. Se trata de un edificio de arquitectura moderna, típica de los años cincuenta y sesenta y que, a mediados de la década de los ochenta, dejó de utilizarse como biblioteca (véase figura 4). 


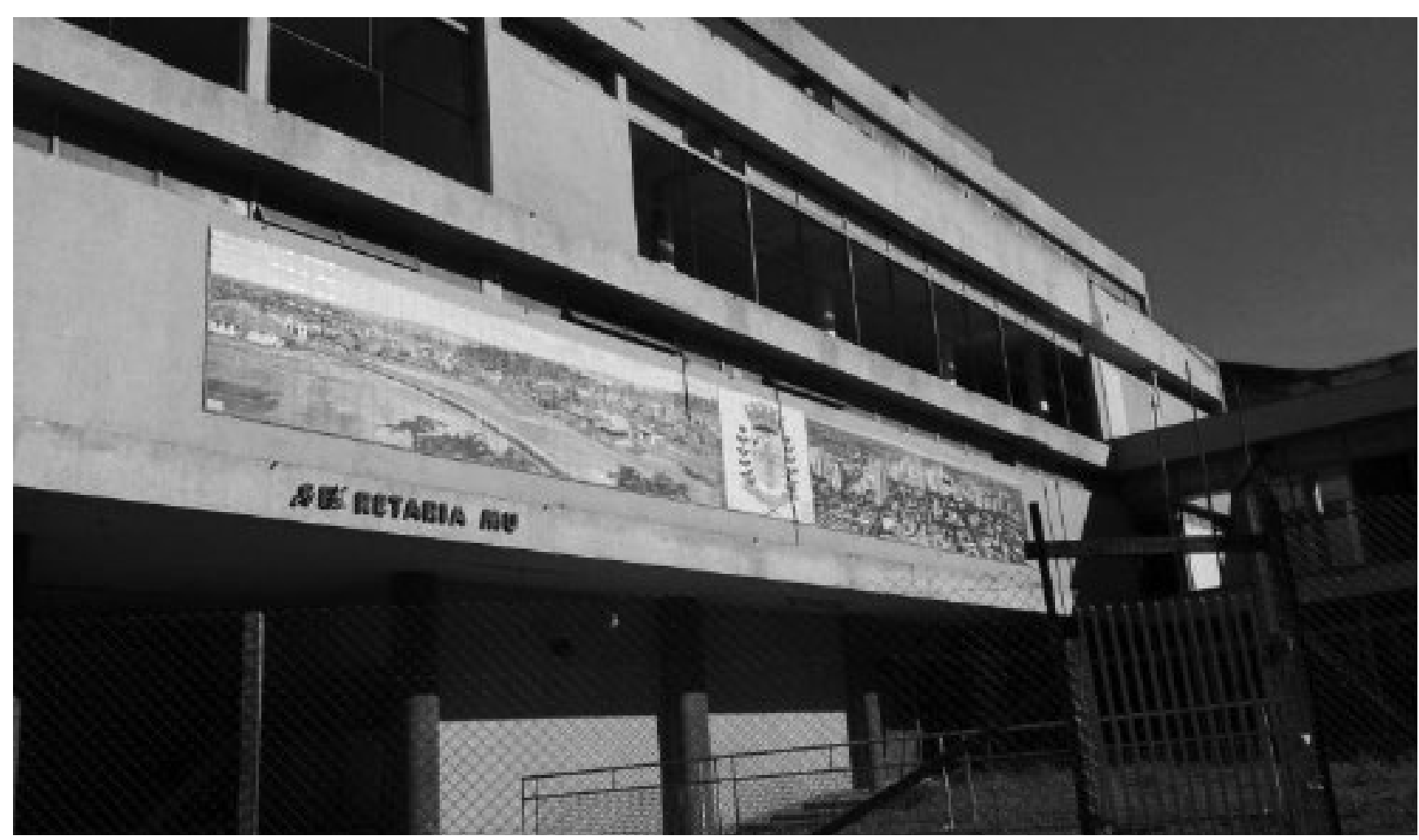

El edificio fue cedido a la Secretaría Municipal de Cultura. Fotografía: Ana Claudia Duarte Pinheiro.

Dicho edificio está desde hace varios años en remodelación. No obstante, las obras están paralizadas por razones políticas y presupuestarias y el aspecto de abandono es evidente. Lo que en algún momento representó a la educación y cultura de la ciudad, se ha descuidado, no sólo por el Gobierno Municipal, sino también por los londrinenses que apenas recuerdan su existencia. Permanece invisible e inerte a todos los que pasan por ese lugar. Otro ejemplo de la violencia estructural integrada a la Londrina cotidiana.

Se observa en las paredes externas del edificio otro mural que se perderá si no se llevan a cabo las remodelaciones previstas o no se despierta el interés de las instituciones que pueden recuperarlo y conservarlo e incluso de la misma sociedad que lo demande. Dicho mural también muestra dos momentos de la historia de la ciudad, la etapa inicial tras la extinción del exuberante bosque, y la década de los años setenta, cuando los edificios de los complejos residenciales y comerciales tomaron la región central de Londrina.

El edificio actual de la Biblioteca Pública Municipal, cuyo nombre hace homenaje a uno de los gober- nadores del estado de Paraná, Prof. Pedro Viriato Parigot de Souza, también fue sujeto de remodelaciones y de cambios en la estructura urbana de Londrina.

Después de que las instalaciones fueron transferidas a varios lugares, la Biblioteca Pública, a partir de I984, comenzó a trabajar en la avenida Río de Janeiro número 413, en la construcción del antiguo Fórum, donde permanece actualmente, a propuesta del Gobierno del Estado de Paraná (véase figura 5). Este cambio llevó a la creación de la Biblioteca Infantil Municipal de Londrina y el Teatro Zaqueo de Melo (antiguo Tribunal Judicial del Foro) como mayor oferta en atención al usuario en mejores condiciones. ${ }^{2}$

Este edificio expone uno de los grandes monumentos de la historia de Londrina al considerar que el viejo centro de la ciudad no es lugar rentable para las nuevas actividades económicas, sociales y económicas de Londrina. La Biblioteca Pública Municipal sustituyó al Fórum Estatal que fue trasladado a principios de los años ochenta al Centro Cívico recién construido al borde del lago Igapó y que reúne a los edificios del Ayuntamiento Municipal, la Cámara de Regidores y el mencionado Foro hasta la actualidad (véase figura 6). 


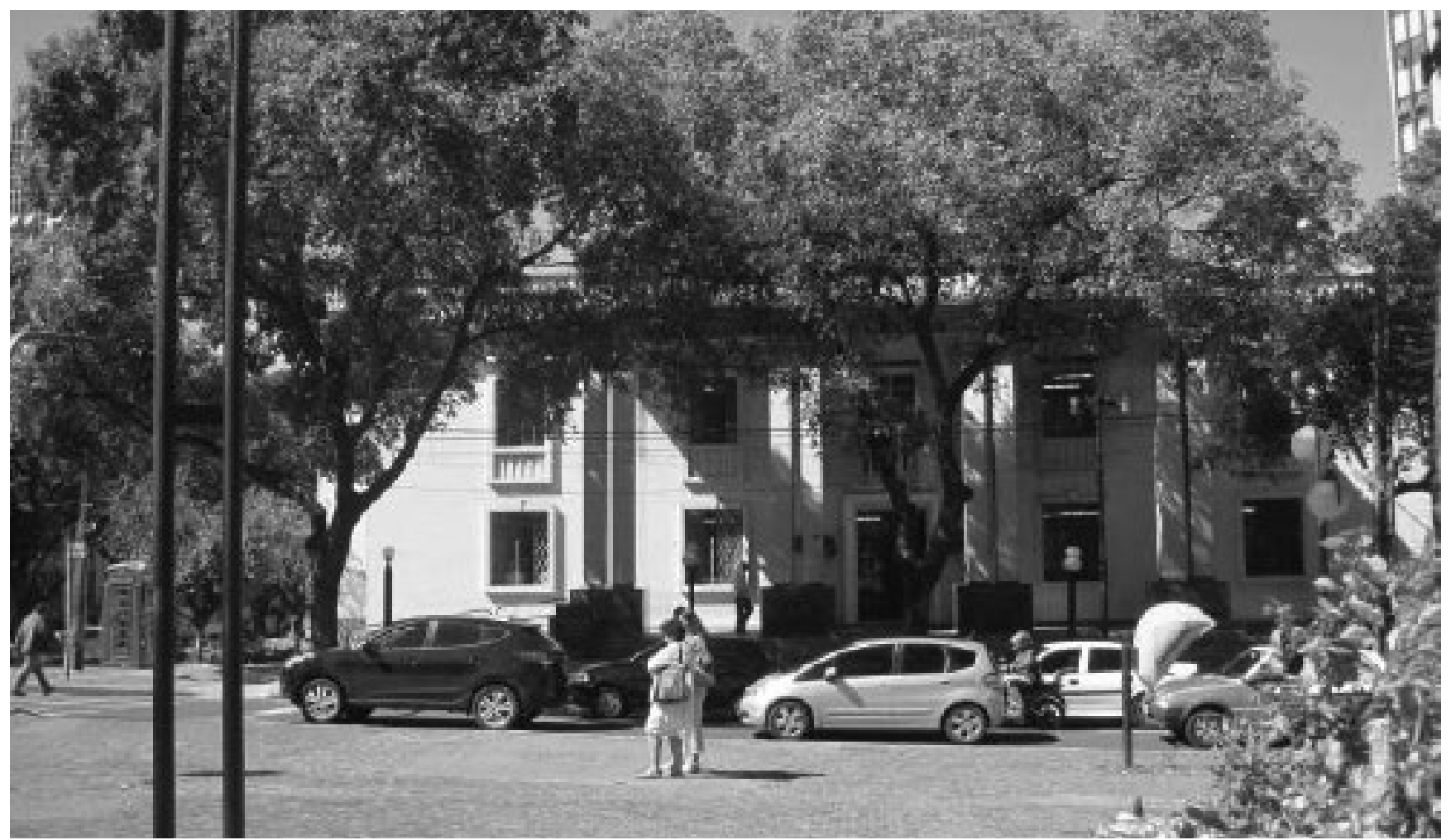

Este edificio sustituyó al Fórum Estatal en la década de los años ochenta. Fotografía: Edward Rodrigo Sánchez Malagón.

Después de la transferencia del Fórum Estatal al Centro Cívico, el edificio estaba en peligro de ser demolido, pero algunos personajes notables de la ciudad, con el apoyo de la población londrinense, fueron capaces de incorporar el edificio a la municipalidad do- nado por el Estado, para instalar la Biblioteca Pública Municipal que venía arrastrando su antigua localización desde el edificio de la Secretaría Municipal de Cultura (mencionado anteriormente), donde permanece en la actualidad.

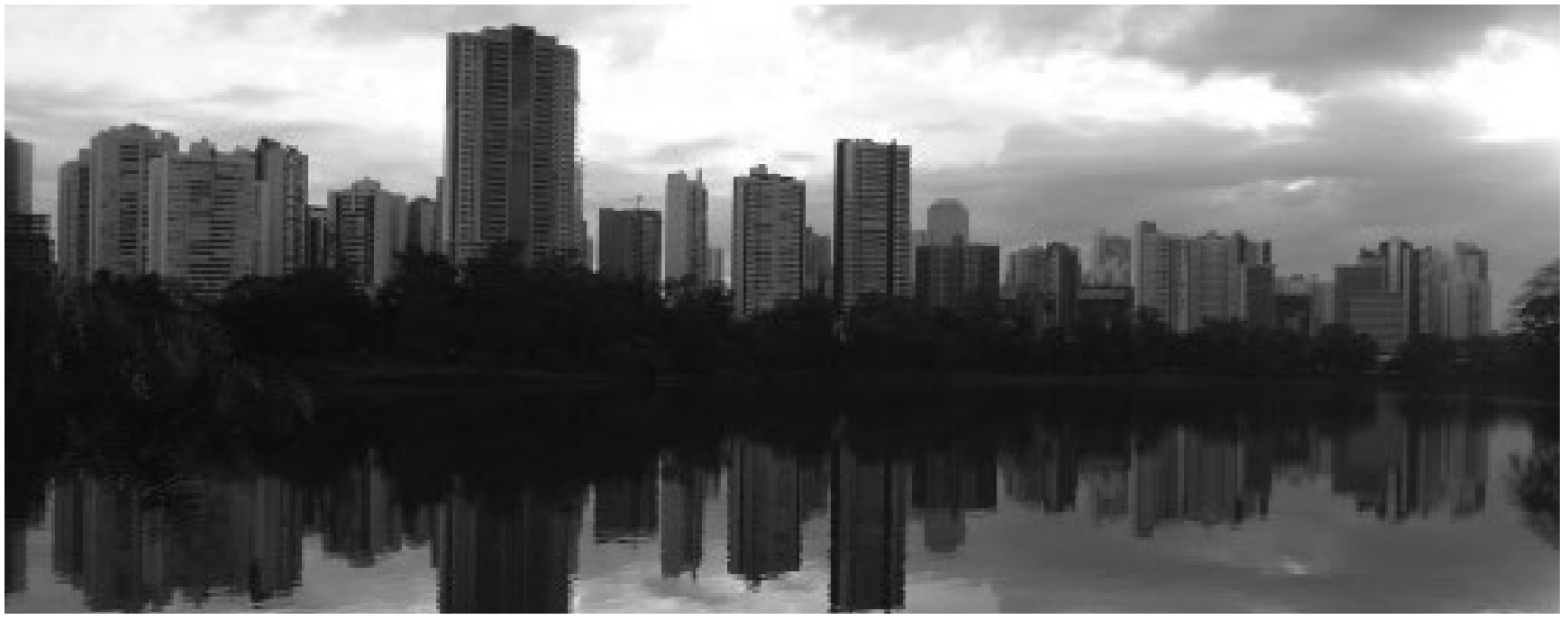

Fotografía: Guadalupe Margarita González Hernández. 
El imponente edificio del antiguo Fórum, donde se realizaban las más diversas y relevantes labores judiciales - civiles y penales y donde estaba el Tribunal de Juicio de los delitos de homicidio y sus tentativas ocurridos en la ciudad (véase figura 7 ) - es un ejemplo de la llamada violencia estructural al formar parte de las dinámicas organizativas de la economía y sociedad urbana londrinense; así como de mostrar las nuevas pautas de la cultura y el arte tendría oportunidad de ser aprovechado para la nueva misión en la educación y la cultura citadina. La permanencia actual de la Biblioteca Pública Municipal en ese edificio es, ahora, una fuente de orgullo para Londrina.

FIGURA 7

Objetos que hacen referencia a la función de origen del edificio de la Biblioteca Pública Municipal

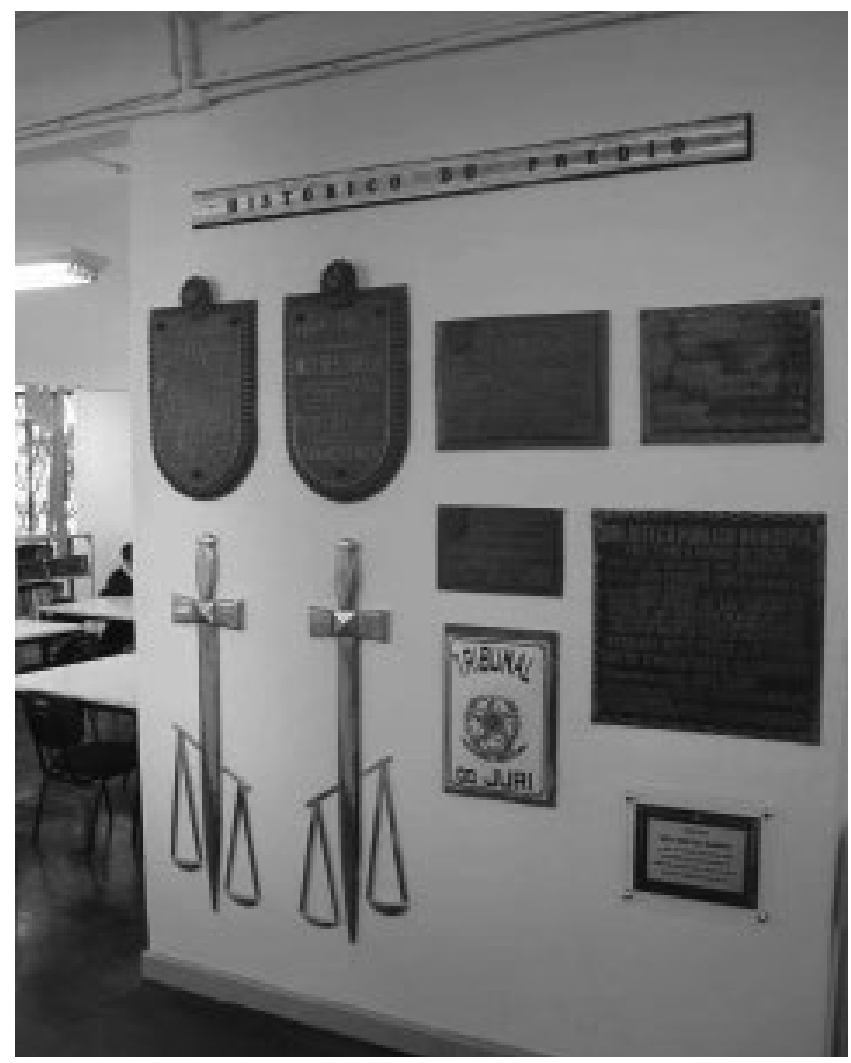

Fotografía de Ana Claudia Duarte Pinheiro.

Internamente, la Biblioteca Pública Municipal cuenta con una colección diversificada y ofrece, además de libros y revistas, acceso a servicios de internet. Según los propios servidores, muchos de ellos a punto de jubilarse, la biblioteca ya no presenta grandes flujos de estudiantes y público en general a causa del uso de nuevas tecnologías que impulsaron la literatura en forma digital. No obstante, se ha dado el caso de que algunos profesores, especialmente de la red pública, están regresando a requerir libros físicamente disponibles.

La biblioteca, además, cuenta con una colección de libros y revistas de la ciudad de Londrina desde sus orígenes hasta la actualidad. Algunos ejemplares son muy viejos para los estándares de una ciudad que aún no ha alcanzado su primer centenario. La Sala Londrina, cuyo mobiliario fue construido a partir de la madera que demolieron de sus extintos bosques y fue recuperada de los contenedores de las fincas de café por el artista local Nilton Marques, mejor conocido como "Poca Marques" (véase figura 8).

La madera utilizada se llama Peroba Rosa, de excelente calidad para la construcción de casas y muebles, fue subutilizada como leña para los hornos industriales de la región y en otras partes. Ahora está prácticamente extinguida en el norte de Paraná. El imponente edificio de la Biblioteca Pública Municipal, con sus servidores orgullosos de estar allí compartiendo sus conocimientos sobre la cultura y la educación, sufre de violencia estructural cada día con la negligencia y desprecio del Estado.

\section{Puerta de acceso a la Sala Londrina en la Biblioteca Pública Municipal}

FiguRA 8

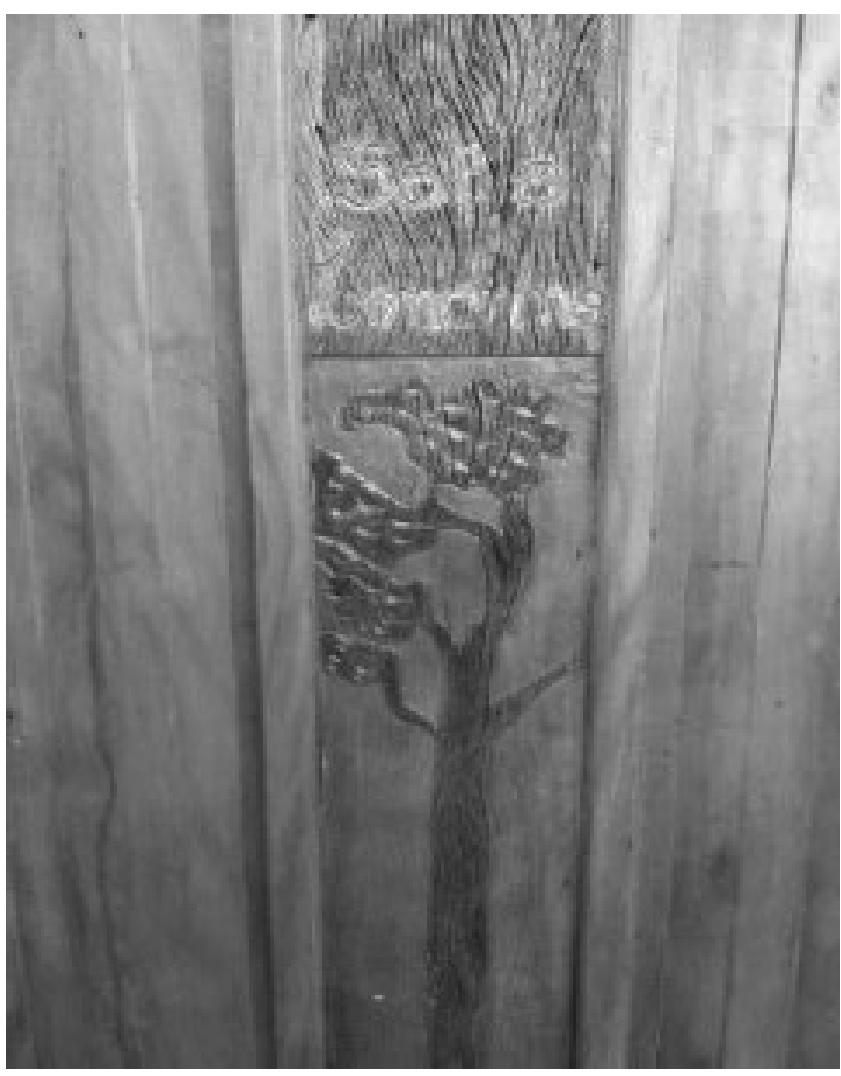

Fotografía de Ana Claudia Duarte Pinheiro. 
Es común ver escenas de improvisación para satisfacer las necesidades de la vida cotidiana. En dicha sala no cuentan con aire acondicionado que permita la conservación adecuada de la colección en los días calurosos del verano tropical brasileño. Se perciben afectaciones tanto en las colecciones como en el edificio-monumento. Otro ejemplo de la violencia estructural que afecta a las instalaciones públicas y socava el desarrollo de la educación y la cultura.

Finalmente, dentro de la Biblioteca Pública Municipal hay una biblioteca infantil que cuenta con una rica colección de libros, revistas y material didáctico para jugar, que incluye copias clásicas de la literatura brasileña.

Aunque la biblioteca infantil es también pública y se ha registrado un número creciente de visitantes, se percibe que no es prioridad en la organización y estrategia mercadotécnica de la Biblioteca Pública Municipal, pues está confinada a la parte trasera de la biblioteca principal, con poca accesibilidad y el espacio es muy pequeño en comparación con el monto de la demanda de niños que saben leer en el municipio. La falta de inversión a espacios públicos y la falta de programas de incentivos a la lectura hacen que la biblioteca infantil sea un ejemplo más de esta violencia estructural en la ciudad y la generación de conocimiento educativo y cultural.

Los grandes cambios de comportamientos sociales ocurridos en la primera década del tercer milenio debido al acceso a las nuevas tecnologías, especial- mente las relacionadas con el internet, condujeron a la no relevancia y deterioro de espacios públicos de esta naturaleza dándose una intensificación al individualismo y consumismo donde las nuevas formas de socialización que se desarrollan actualmente son casi exclusivamente a través las redes sociales.

\section{CONSIDERACIONES FINALES}

El relato histórico y empírico mostró las violencias estructurales y emergentes manifestadas en la intencionalidad del modelo de desarrollo y construcción de las ciudades, donde no es posible identificar condiciones de sostenibilidad social.

El espacio público es un lugar de vital importancia para la ciudad por ser el punto estructurador y ordenador de una realidad social basada en la individualidad y consumismo dejando de lado las prácticas cotidianas de convivencia. El diseño de las actuales ciudades brasileñas, como otros casos latinoamericanos, le apuesta a la rentabilidad a través de la localización estratégica de viviendas y comercio dejando de lado el disfrute de la misma ciudad y sus servicios públicos. En Londrina, al igual que en cualquier ciudad que se sustenta en la lógica de la obtención de la ganancia, merma la memoria y práctica colectiva bajo el descuido de los espacios urbanos públicos aunada a la indiferencia de formas tradicionales de difusión y divulgación del conocimiento.

\section{- notas $\cdot-$}

'Jesús Balbin (2004), "Introducción”, en Jesús Balbin (comp. (2004), Violencias y conflictos urbanos. Un reto para las políticas públicas, Medellín, Instituto Popular de Capacitación, p. 9.

2 René Ornelas (2004), "Experiencia de participación ciudadana en el combate a la inseguridad", en Jesús Balbin (comp.), op.cit., p. 40 .

${ }^{3}$ Guadalupe González (20I4), "Seguridad humana y desarrollo: elementos mínimos para la construcción y discusión de conceptos", Dinâmica Socioambiental e Organização do Espaço, mestrado/doutorado do Programa de Geografia, Universidade Estadual de Londrina, Londrina, agosto.

${ }^{4}$ John Gledhill (2012), "Segurança humana: uma meta viável?", Caderno CRH, vol. 25, núm. 66, pp. 5r9-533.

${ }^{5}$ Rosely Sampaio y Mirian Fernandes (2009), Atlas Urbano de Londrina, Londrina, Universidade Estadual de Londrina, pp. 99 y 65.
${ }^{6}$ William Ribeiro (2003), "A Formação do Centro Principal de Londrina e o Estudo da Centralidade Urbana”, Geografia (Londrina), vol. ı2, núm. 2, julio-diciembre, p. 33.

7 Instituto Brasileiro de Geografia e Estatística (2014), Ciudades@,disponible en http://cidades.ibge.gov.br (consultado el I5 de septiembre de 20I4).

${ }^{8}$ William Ribeiro (2003), op. cit., p. 39.

9 Rosely Sampaio y Miriam Fernandes (2009), op. cit., p. 69.

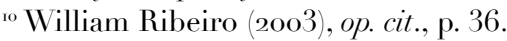

"Jolinda de Moraes (2013), Assistência aos pobre em Londrina: 1940/1980, Londrina, Universidade Estadual de Londrina, pp. $95-96$.

12. Prefeitura de Londrina (2014), disponible en http://ondrina.pr.gov.br (consultado el 2I de agosto de 20I4). 


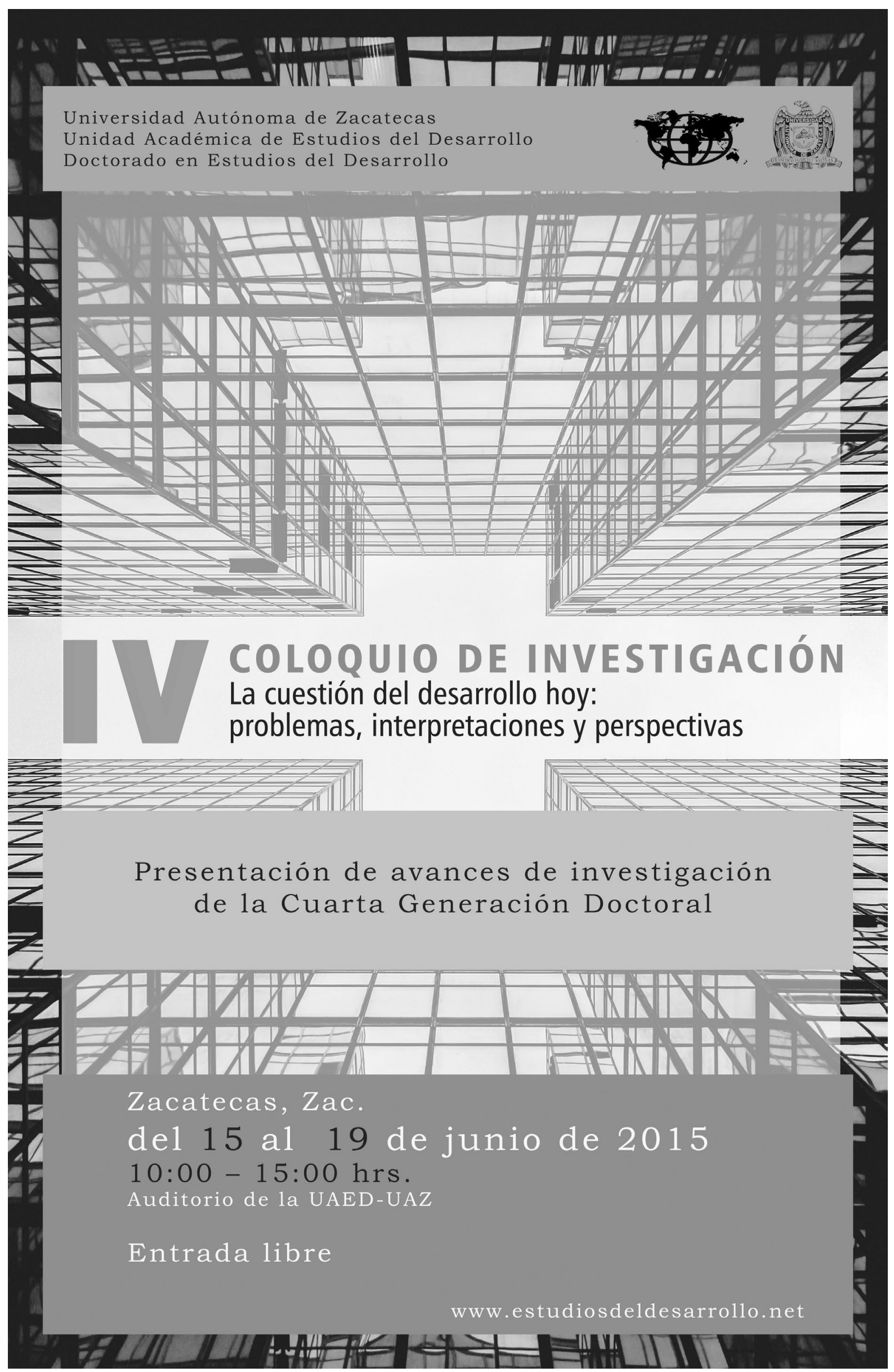

